\title{
Caregivers' treatment-seeking behaviour for children under age five in malaria-endemic areas of rural Myanmar: a cross-sectional study
}

\author{
Moe Moe Thandar ${ }^{1}$, Myat Phone Kyaw², Masamine Jimba ${ }^{1}$ and Junko Yasuoka ${ }^{1 *}$
}

\begin{abstract}
Background: A community-based malaria intervention was introduced through fixed and mobile clinics in rural Myanmar. This study attempted to identify treatment-seeking behaviour of caregivers for children under five and the determinants of appropriate treatment-seeking behaviour in mobile clinic villages (MV) and non-mobile clinic villages (NMV) in malaria-endemic rural areas in Myanmar.
\end{abstract}

Methods: A cross-sectional study was conducted in 23 MV and 25 NMV in Ingapu Township, Myanmar. Appropriate treatment-seeking behaviour was operationally defined as seeking treatment from trained personnel or at a health facility within 24 hours after the onset of fever. Multiple logistic regression analyses were conducted to identify the determinants of appropriate treatment-seeking behaviour.

Results: Among the 597 participants in both types of villages, 166 (35.3\%) caregivers sought appropriate treatment. No significant difference in appropriate treatment-seeking behaviour was found between the two types of villages (adjusted odds ratio (AOR), 0.80; 95\% confidence interval (Cl), 0.51-1.24). Determinants of behaviour include proximity to public health facilities (AOR, 5.86; 95\% Cl, 3.43-10.02), knowledge of malaria (AOR, 1.90; 95\% Cl, 1.14-3.17), malaria prevention behaviour ( $A O R, 1.76 ; 95 \% \mathrm{Cl}, 1.13-2.76)$, treatment at home (AOR, $0.26 ; 95 \% \mathrm{Cl}, 0.15-0.45)$, and treatment and transportation costs (AOR, 0.52; $95 \% \mathrm{Cl}, 0.33-0.83)$.

Conclusions: Caregivers' treatment-seeking behaviour was poor for fever cases among children under age five, and did not differ significantly between MV and NMV. It is necessary to educate caregivers, particularly for early treatment seeking and appropriate use of health care options for fever, and catering to their medical needs. These findings can help promote awareness and prevention, and improve the quality of interventions at the community level.

Keywords: Malaria, Treatment-seeking behaviour, Children under age five, Myanmar

\section{Background}

Malaria is a major health issue in several tropical and subtropical countries [1]. In 2012, there were an estimated 207 million malaria cases and 627,000 malaria deaths, of which $77 \%$ of deaths were children under age five [2]. However, malaria mortality has decreased by more than $25 \%$ since 2000 due to extensive prevention and control measures [3]. Appropriate malaria treatment administered within 24 hours after the onset of fever can help lower it further [4].

\footnotetext{
*Correspondence: jyasuoka@post.harvard.edu

${ }^{1}$ Community and Global Health Department, Graduate School of Medicine, the University of Tokyo, Tokyo, Japan

Full list of author information is available at the end of the article
}

Although malaria is typically treated at health facilities, diagnosis and treatment at community level is effective when access to such facilities is limited. The effectiveness of community-level malaria control measures is influenced by early recognition of symptoms and subsequent treatmentseeking behaviour [5]. It is therefore crucial to obtain region-specific information on treatment-seeking behaviour for malaria, the use of anti-malarial drugs, and obstacles to treatment [6,7].

Malaria treatment-seeking behaviours are also associated with socio-economic, demographic and personal factors. Other important factors are proximity to health facilities, availability of transportation, knowledge of malaria, a history of malaria, cultural beliefs regarding 
traditional and herbal medicines, satisfaction with health services, and attitude towards health care providers [1,8-13].

In Myanmar, malaria is of national concern. Approximately $63 \%$ of the country's population lives in malariaaffected areas. Three major post-natal causes of deaths among one- to 59-months-old children are pneumonia, diarrhoea and malaria [14]. Over the past 20 years, the National Malaria Control Programme (NMCP) has made considerable progress in malaria control. Yet the proportion of under-five children who received anti-malarial drugs was well below $60 \%$, and the proportion of underfive children sleeping under insecticide-treated nets was less than $40 \%$ in 2008 [15].

Data on malaria-related treatment-seeking behaviours are limited [12]; the only available data found that selftreatment and seeking assistance from drug vendors were the most common practices in Teikkyi township and Shan Special Region II [12,16]; and in the ChinaMyanmar border area, only $32.0 \%$ of malaria patients sought treatment within 24 hours and $20.1 \%$ were tested for confirming diagnosis [12].

A Myanmar Medical Association-Malaria (MMAMalaria) project has been implementing a communitybased malaria control programme that promotes the rational use of government-recommended anti-malarial drugs and rapid diagnostic tests (RDT). It also introduces fixed and mobile clinics, and recruits village malaria volunteers in malaria-endemic townships for diagnosis and treatment.

However, little is known about treatment-seeking behaviour after introducing this malaria control programme in communities. To evaluate such control programmes, it is critical to obtain baseline information at the initial stages of programme implementation. Therefore, this study attempted to identify caregivers' treatment-seeking behaviour for children under five and determinants of appropriate treatment-seeking behaviour in mobile clinic villages (MV) and non-mobile clinic villages (NMV) in malariaendemic rural areas in Myanmar.

\section{Methods}

\section{Study area}

This cross-sectional study was conducted in Ingapu Township, Ayeyarwaddy region, Myanmar. Of 213,064 residents in the township, 22,790 are children under age five. Thirty-one per cent of the total population in Ingapu Township is at high risk for malaria [17]. Malaria morbidity was 16.78 per 1,000 individuals and mortality was 3.75 per 100,000 cases in 2011. The MMA-Malaria project has conducted a malaria control programme through fixed and mobile clinics and village volunteers in this township since 2012. One fixed clinic is located at Kwin Kaut town and 34 malaria-endemic villages were selected for mobile clinic visits based on malaria incidences and accessibility. One volunteer in each selected village was recruited for the period between the mobile clinic visits. The mobile team and volunteers provided malaria diagnosis and treatment, and confirmed malaria patients were provided with malaria-related health education by using pamphlets and long-lasting insecticide nets (LLIN). These activities were gradually expended to 34 villages by June 2013 .

\section{Sampling method}

Of the 34 malaria-endemic villages where the MMAMalaria project intervention was introduced, $23 \mathrm{MV}$ were randomly selected for the study. Out of 225 malaria-endemic villages without MMA-Malaria project intervention, 25 non-intervention villages were selected as a comparison group (NMV), ensuring similarity in residents' demographics, socio-economic status, geographical location, and proximity to fixed clinics. Villages with rural health centres (RHCs) were excluded. Depending on the population of the village (150-500 residents), approximately 12 participants from each village were selected.

\section{Participants}

Study participants were caregivers of children under five years who had a history of fever during the two months preceding the study. Caregivers were mothers or other family members who were most responsible for attending to their child's health. Caregivers younger than 18 years and those with mental health problems were excluded. Further, those whose children were ill at the time of the interview were also excluded, as they were likely to seek health care until the child was cured. In high-risk areas, malaria is suspected in every fever case. Therefore, in this study seeking treatment within 24 hours after the fever was set as the indicator of appropriate treatment-seeking behaviour $[12,13]$.

\section{Sample size calculation}

The sample size was calculated using Epi Info 7 (Centers for Disease Control and Prevention, Atlanta, Georgia). The test's power was $80 \%$ with a $95 \%$ confidence interval. Due to limited data about treatment-seeking behaviour for children under five, the prevalence of the dependent variable was estimated to be $70 \%$ for this study, based on a previous study in Bago Region in Myanmar [18]. This resulted in a minimum sample size of 246 participants in one group. To compensate for missing responses, at least 300 participants for each group were recruited in this study.

\section{Measurements and variables}

A structured questionnaire was developed based on the WHO Malaria Indicator Survey tool [19] and relevant studies [20-23]. The questionnaire was first developed in 
English, translated into Myanmar language, and translated back into English by experts on public health and malaria in Myanmar. The questionnaire was pre-tested in a village with comparable proximity and demographic distribution to the selected villages before finalizing the instrument for data collection. The questionnaire contained four major domains: socio-demographic characteristics, knowledge of malaria, malaria prevention behaviour, and malaria treatment-seeking behaviour.

\section{Outcome variables}

The outcome variable was appropriate treatmentseeking behaviour, operationally defined as seeking treatment from trained personnel or at a health facility within 24 hours of the onset of fever [24]. In this study, the first treatment source sought by caregivers was examined if it was trained personnel or health facility. If not, the treatment-seeking behaviour was considered inappropriate.

\section{Independent variables}

Socio-economic and personal factors are known to influence treatment-seeking behaviour. The following were included as independent variables: participants' age, sex [12], level of education, occupation $[1,9,10]$, income $[1,12]$, proximity to public health services [1], knowledge of malaria [9], prevention behaviour [20] and type of village (MV or NMV).

\section{Knowledge of malaria}

Seven components of knowledge about malaria were measured: symptoms, cause, vulnerable groups, prevention, diagnosis, treatment, and government recommended medication. Each component was assessed by multiple-choice questions, awarded one point for each correct answer. The scores for each component were summed to yield the total knowledge index. The knowledge index scores were categorized into a high and low group, using the median [21,22].

\section{Malaria prevention behaviour}

Malaria prevention behaviours were measured using a single question with multiple correct choices. Each malaria prevention measure that the participant selected was awarded one point and the total score was summed. The final scores were categorized into a high and low group, using the median [22].

\section{Data collection}

Data were collected in the monsoon season when malaria transmission is high, from August to September 2013. The lead researcher and three trained interviewers conducted face-to-face interviews for about 30 minutes. The interviewers informed caregivers about the purpose and procedure of the research and ensured that confidentiality would be maintained.

In each village, interviewers visited every accessible household to screen them for the study by inquiring whether any children under age five had a history of fever in the previous two months. If there was more than one child with a history of fever in the previous two months, the history of the most recent child was obtained. In total, 302 participants were selected for the survey in MV and 300 participants in NMV.

\section{Data analysis}

After data collection, data were coded and entered using EpiData and analysed with SPSS version 16 (SPSS Inc, Chicago, IL, USA). Of the 602 participants, five were under the age of 18 years, therefore data of 597 caregivers were used. Frequencies and proportions were used for descriptive data. Independent t-tests were used to compare age, number of household members, number of children under five, and income. Chi-square test and Fisher's exact test were used to compare the differences in proportions. To represent appropriate treatment-seeking behaviour, the time taken to seek treatment and health service provider sought were combined and then categorized into four groups. The first group comprised caregivers who sought treatment at a health facility or from trained personnel within 24 hours. The second comprised caregivers who sought treatment within 24 hours, but not at a health facility or from trained personnel. The third comprised caregivers who sought treatment at a health facility or from trained personnel, but not within 24 hours. The fourth group comprised caregivers who did not seek treatment at a health facility or from trained personnel, nor sought treatment within 24 hours. The first group was termed 'caregivers with appropriate treatment-seeking behaviour'; the three remaining groups were termed 'caregivers without appropriate treatment-seeking behaviour'.

To examine appropriate treatment-seeking behaviour, all study participants' data were combined and two kinds of analyses were performed. First, descriptive analyses were conducted to examine differences in characteristics of caregivers who demonstrated appropriate treatmentseeking behaviour and those who did not. Second, multiple logistic regression was performed to identify the determinants of appropriate treatment-seeking behaviour. Type of village (MV and NMV) was set as an independent variable in multiple logistic regression analysis. Multicollinearity among independent variables was tested before logistic regression. Potential confounders included level of education, occupation and income. All continuous variables were converted to dichotomous variables for multiple logistic regression analysis using the sample median and statistical significance was set at $\mathrm{p}<0.05$. 


\section{Ethical considerations}

Ethical approval was obtained from the Research Ethics Committee of the Graduate School of Medicine, the University of Tokyo, Japan, and the Department of Medical Research (Lower Myanmar), Ministry of Health, Yangon, Myanmar. Upon explaining the objectives of the study, written consent was obtained from all respondents and confidentiality was maintained.

Participants' names were not recorded; instead, identification numbers were used. All the information was treated confidentially and only available to those who directly concerned with this research.

\section{Results}

\section{Socio-demographic characteristics of participants}

In total, 597 caregivers participated in this study (see Table 1). Almost all participants were mothers, married and of Burma ethnicity. Participants' mean age was 31.5 years (range: $18-75$ years). The mean age of children under five with a history of fever during the two months before the interview was 27.4 months (range: 259 months); $53.1 \%$ of the children were boys.

No significant differences between MV and NMV were observed for socio-demographic characteristics, except for occupation, income and nearest health service provider. In MV, $23.5 \%$ of residents were forest workers, while $10.1 \%$ were forest workers in NMV $(\mathrm{p}=0.001)$; $44.1 \%$ in $\mathrm{MV}$ as opposed to $33.9 \%$ in NMV had a monthly income of more than 60US\$ $(p=0.011)$. In both types of villages, the closest health service providers were drug stores (MV 57.5\% vs NMV 53.7\%), followed by midwives (MV 22.7\% vs NMV 20.8\%).

\section{Caregivers' treatment-seeking behaviour}

In more than $80 \%$ of the households mothers were the decision-makers for seeking treatment outside the home in both types of villages (see Table 2). More than $50 \%$ of the caregivers did not medicate at home before seeking treatment, and more than $66 \%$ sought treatment outside the home in both types of villages. About $90 \%$ of the caregivers raised "disease severity" as the most important deciding factor to seek treatment. In both types of villages, more than $50 \%$ of the caregivers sought treatment within 24 hours of the onset of fever and was comparative across MV (57\%) and NMV (62\%).

The most frequented primary health service provider was the midwife $(31.9 \%)$ for caregivers who sought treatment outside the home in MV $(\mathrm{n}=229)$, whereas in NMV $(\mathrm{n}=241)$, the drug stores were the most frequented primary source for treatment $(27.0 \%)(p=0.041)$. Only $2.6 \%$ of caregivers sought treatment from mobile clinics or malaria volunteers in MV. Further, $49.3 \%$ of caregivers took longer than 15 minutes to reach the first source for treatment in MV as opposed to $39.0 \%$ in NMV ( $=0.024)$.
Table 1 Socio-demographic characteristics of participants

\begin{tabular}{|c|c|c|c|c|c|}
\hline \multirow[t]{2}{*}{ Variables } & \multicolumn{2}{|c|}{ MV $(n=299)$} & \multicolumn{2}{|c|}{ NMV $(n=298)$} & \multirow[b]{2}{*}{$\mathrm{p}$ value } \\
\hline & $\mathrm{n}$ & $\%$ & $\mathrm{n}$ & $\%$ & \\
\hline \multicolumn{6}{|l|}{ Number of household members } \\
\hline$\leq 4$ & 183 & 61.2 & 183 & 61.4 & 0.959 \\
\hline$>4$ & 116 & 38.8 & 115 & 38.6 & \\
\hline \multicolumn{6}{|l|}{$\begin{array}{l}\text { Number of children } \\
\text { U5 at home }\end{array}$} \\
\hline 1 & 271 & 90.6 & 265 & 88.9 & 0.491 \\
\hline$>1$ & 28 & 9.4 & 33 & 11.1 & \\
\hline \multicolumn{6}{|l|}{ Children's age (months) } \\
\hline$\leq 27$ & 158 & 52.8 & 159 & 53.4 & 0.900 \\
\hline$>27$ & 141 & 47.2 & 139 & 46.6 & \\
\hline \multicolumn{6}{|l|}{ Children's sex } \\
\hline Male & 156 & 52.2 & 161 & 54.0 & 0.650 \\
\hline Female & 143 & 47.8 & 137 & 46.0 & \\
\hline \multicolumn{6}{|l|}{ Caregivers' age (years) } \\
\hline$\leq 30$ & 170 & 56.9 & 155 & 52.0 & 0.235 \\
\hline$>30$ & 129 & 43.1 & 143 & 48.0 & \\
\hline \multicolumn{6}{|l|}{ Relationship to child } \\
\hline Mother & 271 & 90.6 & 270 & 90.6 & 0.989 \\
\hline Other & 28 & 9.4 & 28 & 9.4 & \\
\hline \multicolumn{6}{|l|}{ Level of education } \\
\hline Illiterate & 22 & 7.4 & 21 & 7.0 & 0.984 \\
\hline Primary school & 209 & 69.9 & 208 & 69.8 & \\
\hline Secondary school or higher & 68 & 22.7 & 69 & 23.2 & \\
\hline \multicolumn{6}{|l|}{ Occupation } \\
\hline Farmer & 116 & 38.9 & 123 & 41.4 & 0.001 \\
\hline Forest worker & 70 & 23.5 & 30 & 10.1 & \\
\hline Other & 112 & 37.6 & 144 & 48.5 & \\
\hline \multicolumn{6}{|l|}{ Income (US\$) } \\
\hline$\leq 60$ & 165 & 55.9 & 197 & 66.1 & 0.011 \\
\hline$>60$ & 130 & 44.1 & 101 & 33.9 & \\
\hline \multicolumn{6}{|l|}{ Nearest health service* } \\
\hline Drug store & 172 & 57.5 & 160 & 53.7 & $<0.001$ \\
\hline Midwife & 68 & 22.7 & 62 & 20.8 & \\
\hline Charlatan/traditional healer & 29 & 9.7 & 35 & 11.7 & \\
\hline Malaria volunteer & 17 & 5.7 & 0 & 0.0 & \\
\hline Rural health centre & 9 & 3.0 & 31 & 10.4 & \\
\hline General practitioner & 4 & 1.3 & 10 & 3.4 & \\
\hline \multicolumn{6}{|l|}{ Mode of transportation } \\
\hline On foot & 260 & 87.0 & 149 & 83.6 & 0.241 \\
\hline By vehicle & 39 & 13.0 & 49 & 16.4 & \\
\hline \multicolumn{6}{|l|}{ Duration } \\
\hline Within $30 \mathrm{~min}$ & 291 & 97.3 & 287 & 96.3 & 0.480 \\
\hline More than $30 \mathrm{~min}$ & 8 & 2.7 & 11 & 3.7 & \\
\hline
\end{tabular}

Notes: MV: Mobile clinic villages; NMV: non-mobile clinic villages; children U5: children under five; Chi-square test $\mathrm{p}$-vale (*Fisher's exact test). 
Table 2 Caregivers' treatment-seeking behaviour

\begin{tabular}{|c|c|c|c|c|c|}
\hline \multirow[t]{2}{*}{ Variables } & \multicolumn{2}{|c|}{$M V(n=299)$} & \multicolumn{2}{|c|}{ NMV $(n=298)$} & \multirow[b]{2}{*}{$p$ value } \\
\hline & $\mathrm{n}$ & $\%$ & n & $\%$ & \\
\hline \multicolumn{6}{|l|}{ Decision-maker for seeking treatment } \\
\hline Mother & 246 & 82.3 & 251 & 84.2 & 0.523 \\
\hline Other & 53 & 17.7 & 47 & 15.8 & \\
\hline \multicolumn{6}{|l|}{ Deciding factor } \\
\hline Disease severity & 272 & 91.3 & 265 & 88.9 & 0.337 \\
\hline Other & 26 & 8.7 & 33 & 11.1 & \\
\hline \multicolumn{6}{|l|}{ Treatment at home } \\
\hline Yes & 127 & 42.5 & 115 & 38.6 & 0.334 \\
\hline No & 172 & 57.5 & 183 & 61.4 & \\
\hline \multicolumn{6}{|l|}{ Treatment outside } \\
\hline Yes & 229 & 76.6 & 241 & 80.9 & 0.201 \\
\hline No & 70 & 5.8 & 57 & 19.1 & \\
\hline \multicolumn{6}{|l|}{ Reason for not receiving treatment } \\
\hline Quick recovery & 47 & 67.1 & 44 & 77.2 & 0.211 \\
\hline Other & 23 & 32.9 & 13 & 22.8 & \\
\hline \multicolumn{6}{|l|}{ Time taken to seek treatment } \\
\hline Within 24 hours & 131 & 57.2 & 150 & 62.2 & 0.441 \\
\hline Other & 98 & 42.8 & 91 & 37.8 & \\
\hline \multicolumn{6}{|l|}{ Primary health service provider* } \\
\hline Midwife & 73 & 31.9 & 58 & 24.1 & 0.041 \\
\hline GP & 62 & 27.1 & 62 & 25.7 & \\
\hline Drug store & 55 & 24.0 & 65 & 27.0 & \\
\hline Charlatan/traditional healer & 15 & 6.6 & 20 & 8.3 & \\
\hline $\mathrm{RHC}$ & 14 & 6.1 & 31 & 12.9 & \\
\hline Malaria volunteer/mobile clinic & 6 & 2.6 & 1 & 0.4 & \\
\hline Hospital & 4 & 1.7 & 4 & 1.7 & \\
\hline \multicolumn{6}{|c|}{ Reason for choosing primary health service } \\
\hline Trust & 111 & 48.5 & 117 & 48.5 & 0.097 \\
\hline Proximity & 64 & 27.9 & 54 & 22.4 & \\
\hline Other & 28 & 12.3 & 41 & 17.0 & \\
\hline Famous & 10 & 4.4 & 5 & 2.1 & \\
\hline Inexpensive & 16 & 7.0 & 24 & 10.0 & \\
\hline \multicolumn{6}{|l|}{ Mode of transportation } \\
\hline On foot & 108 & 47.2 & 119 & 49.4 & 0.807 \\
\hline Motorbike & 68 & 29.7 & 72 & 29.9 & \\
\hline Other & 53 & 23.1 & 50 & 20.7 & \\
\hline \multicolumn{6}{|l|}{ Blood test } \\
\hline Yes & 17 & 7.4 & 16 & 6.6 & 0.739 \\
\hline No & 212 & 92.6 & 225 & 93.4 & \\
\hline \multicolumn{6}{|c|}{ Location where blood test was conducted* } \\
\hline Midwife & 5 & 29.4 & 6 & 37.5 & 0.230 \\
\hline GP & 7 & 41.2 & 3 & 18.8 & \\
\hline
\end{tabular}


Table 2 Caregivers' treatment-seeking behaviour (Continued)

\begin{tabular}{|c|c|c|c|c|c|}
\hline Hospital/RHC & 2 & 11.8 & 6 & 37.5 & \\
\hline Malaria volunteer/mobile clinic & 3 & 17.6 & 1 & 6.3 & \\
\hline \multicolumn{6}{|l|}{ Health education conducted with patient } \\
\hline Drug timetable & 7 & 87.5 & 5 & 100.0 & 0.411 \\
\hline Drug compliance & 7 & 87.5 & 5 & 100.0 & 0.411 \\
\hline Preparedness for worsened symptoms* & 6 & 75.0 & 2 & 40.0 & 0.293 \\
\hline Follow up* & 2 & 25.0 & 2 & 40.0 & 1.000 \\
\hline Severe malarial symptoms* & 2 & 25.0 & 1 & 20.0 & 1.000 \\
\hline Side effects* & 1 & 12.5 & 0 & 0.0 & 1.000 \\
\hline \multicolumn{6}{|l|}{ Total cost (US\$) } \\
\hline$\leq 1.1$ & 111.0 & 48.5 & 125 & 51.9 & 0.462 \\
\hline$>1.1$ & 118.0 & 51.5 & 116 & 48.1 & \\
\hline \multicolumn{6}{|l|}{ Used MMA service } \\
\hline Yes & 52 & 17.4 & 32 & 10.7 & 0.019 \\
\hline No & 247 & 82.6 & 266 & 89.3 & \\
\hline
\end{tabular}

Notes: MV: Mobile clinic villages; NMV: non-mobile clinic villages; GP: general practitioner; RHC: rural health centre; MMA: Myanmar Medical Association; Chi-square test $p$-vale (*Fisher's exact test).

In $\mathrm{MV}$, of the total 229 children who received treatment outside their homes, 17 were tested for malaria; 15 (6.6\%) children received a malaria diagnosis using blood tests with RDT, and two children $(0.9 \%)$ received a diagnosis using microscopy. In NMV, of the total 241 children who received treatment outside home, 16 children were tested for malaria; blood test with RDT were conducted on 15 children $(6.2 \%)$ and one child $(0.4 \%)$ received a diagnosis with microscopy. In MV, blood tests were conducted most frequently at general practitioners' (GPs) clinics, while in NMV, public health facilities (midwives, hospitals, and RHCs) were most frequently visited for blood tests. Only five children in MV and three in NMV received positive results for malaria on the blood test.

In both types of villages, 88 caregivers consulted more than one health service provider and 20 caregivers consulted three providers. When mobile clinics and malaria volunteers were sought, they were always the first-choice health service provider (data not shown in Table). Fiftytwo caregivers (17.4\%) from MV and 32 caregivers (10.7\%) from NMV had sought MMA mobile clinics or malaria volunteers at least once $(\mathrm{p}=0.019)$.

\section{Caregivers' knowledge of malaria}

In both types of villages, more than $85 \%$ of the caregivers stated chills and rigor as symptoms of malaria (see Table 3). More than $60 \%$ in both types of villages included sweating as a symptom of malaria. About $50 \%$ of caregivers in both types of villages were aware that children under five were especially vulnerable to malaria infection and more than $90 \%$ knew that mosquito bites cause malaria.
In both types of villages, more than $80 \%$ of caregivers answered malaria could be prevented by using mosquito nets or LLIN. Nearly $80 \%$ of respondents in both types of villages answered that malaria could be diagnosed by blood tests and over 90\% knew that malaria could be treated using anti-malarial drugs. Moreover, $55.0 \%$ of caregivers in MV compared to $75.8 \%$ in NMV could provide the name of the recommended drug $(p=0.010)$.

\section{Caregivers' malaria prevention behaviour}

In both types of villages, the most popular method for malaria prevention, with nearly $100 \%$ response rate, was using bed nets (see Table 4). This was followed by avoiding mosquito bites (more than 92\%), and wearing long-sleeved shirts and trousers (more than 71\%) in both villages. The use of LLIN was low in both types of villages (less than 15\%).

\section{Determinants of appropriate treatment-seeking behaviour}

Table 5 shows the determinants of appropriate treatmentseeking behaviour. Proximity to public health facilities was positively associated with appropriate treatment-seeking behaviour (adjusted odds ratio (AOR), 5.86; confidence interval (CI), 3.43-10.02). Caregivers who gave their child any medicine at home before seeking treatment outside were less likely to seek appropriate treatment (AOR, 0.26; CI, 0.15-0.45). Caregivers who spent less on treatment and transportation to the nearest health services were less likely to seek appropriate treatment $(\mathrm{AOR}=0.52$; CI 0.330.83). Compared to caregivers who had low levels of knowledge, caregivers with high levels of knowledge were more likely to seek appropriate treatment $(\mathrm{AOR}=1.90$; $\mathrm{CI}$ 
Table 3 Caregivers' knowledge of malaria

\begin{tabular}{|c|c|c|c|c|c|}
\hline \multirow[t]{2}{*}{ Variables } & \multicolumn{2}{|c|}{ MV $(n=299)$} & \multicolumn{2}{|c|}{$\operatorname{NMV}(n=298)$} & \multirow[b]{2}{*}{$\mathrm{p}$ value } \\
\hline & $\mathrm{n}$ & $\%$ & $\mathrm{n}$ & $\%$ & \\
\hline \multicolumn{6}{|l|}{ Symptoms } \\
\hline Fever (yes) & 270 & 95.4 & 263 & 97.4 & 0.208 \\
\hline Chills and rigors (yes) & 248 & 87.6 & 255 & 94.4 & 0.005 \\
\hline Headache (yes) & 211 & 74.6 & 215 & 79.6 & 0.156 \\
\hline Sweating (yes) & 177 & 62.5 & 202 & 74.8 & 0.002 \\
\hline \multicolumn{6}{|l|}{ Vulnerable groups } \\
\hline Under-five children (yes) & 162 & 57.2 & 132 & 48.9 & 0.049 \\
\hline Pregnant mothers (yes) & 139 & 49.1 & 116 & 43.0 & 0.147 \\
\hline Forest workers (yes) & 256 & 90.5 & 248 & 91.9 & 0.565 \\
\hline Farmers (yes) & 170 & 60.1 & 150 & 55.6 & 0.282 \\
\hline \multicolumn{6}{|l|}{ Causes } \\
\hline Mosquito bite (yes) & 279 & 98.6 & 256 & 94.8 & 0.012 \\
\hline Coughing and sneezing (no) & 46 & 16.3 & 51 & 18.9 & 0.415 \\
\hline Contact (no) & 83 & 29.3 & 81 & 30.0 & 0.863 \\
\hline Drinking (no) & 43 & 15.2 & 37 & 13.7 & 0.618 \\
\hline Bathing (no) & 63 & 22.3 & 48 & 17.8 & 0.188 \\
\hline Eating bananas (no) & 74 & 26.1 & 63 & 23.3 & 0.443 \\
\hline \multicolumn{6}{|l|}{ Prevention method } \\
\hline Use mosquito/bed net (yes) & 245 & 86.6 & 237 & 87.8 & 0.672 \\
\hline Use LLIN (yes) & 239 & 84.5 & 228 & 84.4 & 0.998 \\
\hline Avoid mosquito bites (yes) & 235 & 83.0 & 234 & 86.7 & 0.235 \\
\hline Use mosquito coil (yes) & 196 & 69.3 & 202 & 74.8 & 0.146 \\
\hline Use mosquito repellent (yes) & 158 & 55.8 & 139 & 51.5 & 0.305 \\
\hline $\begin{array}{l}\text { Wear long-sleeved } \\
\text { clothing (yes) }\end{array}$ & 219 & 77.4 & 209 & 77.4 & 0.995 \\
\hline Clean environment (yes) & 247 & 87.3 & 235 & 87.0 & 0.932 \\
\hline Cover water containers (yes) & 241 & 85.2 & 235 & 87.0 & 0.524 \\
\hline \multicolumn{6}{|l|}{ Diagnosis } \\
\hline Blood test (yes) & 225 & 79.5 & 220 & 81.5 & 0.558 \\
\hline Fever with chills and rigor (no) & 196 & 37.5 & 114 & 42.2 & 0.252 \\
\hline Observation (no) & 26 & 9.2 & 22 & 8.1 & 0.664 \\
\hline \multicolumn{6}{|l|}{ Curable drugs } \\
\hline Anti-malarials (yes) & 169 & 91.4 & 165 & 91.2 & 0.948 \\
\hline Antibiotics (no) & 94 & 50.8 & 89 & 49.2 & 0.754 \\
\hline Traditional medicine (no) & 64 & 34.6 & 70 & 38.7 & 0.418 \\
\hline Vitamins (no) & 83 & 44.9 & 99 & 54.7 & 0.060 \\
\hline $\begin{array}{l}\text { Government recommended } \\
\text { drug (Coartem) }\end{array}$ & 44 & 55.0 & 47 & 75.8 & 0.010 \\
\hline
\end{tabular}

Notes: MV: Mobile clinic villages; VWOMC: non-mobile clinic villages; LLIN: long-lasting insecticide nets; Chi-square test p-vale.

1.14-3.17). Similarly, caregivers who had high levels of malaria prevention behaviour were more likely to seek appropriate treatment $(\mathrm{AOR}=1.76$; CI 1.13-2.76).
Table 4 Caregivers' malaria prevention behaviour

\begin{tabular}{|c|c|c|c|c|c|}
\hline \multirow[t]{2}{*}{ Variables } & \multicolumn{2}{|c|}{ MV $(n=299)$} & \multicolumn{2}{|c|}{ NMV $(n=298)$} & \multirow[b]{2}{*}{$p$ value } \\
\hline & $\mathrm{N}$ & $\%$ & $\mathrm{n}$ & $\%$ & \\
\hline \multicolumn{6}{|l|}{ Preventive action } \\
\hline Using mosquito/bed net & 278 & 98.2 & 270 & 100.0 & 0.028 \\
\hline Avoid mosquito bites & 262 & 92.6 & 256 & 94.8 & 0.281 \\
\hline $\begin{array}{l}\text { Wearing long-sleeved } \\
\text { clothing }\end{array}$ & 221 & 78.1 & 194 & 71.9 & 0.090 \\
\hline Using mosquito coil & 160 & 56.5 & 137 & 50.7 & 0.172 \\
\hline Using LLIN & 34 & 12.0 & 39 & 14.4 & 0.399 \\
\hline Using mosquito repellent & 10 & 3.5 & 14 & 5.2 & 0.341 \\
\hline
\end{tabular}

\section{Discussion}

This study revealed several important findings regarding caregivers' treatment-seeking behaviour for children under age five in malaria endemic areas of rural Myanmar. First, caregivers' treatment-seeking behaviour was poor; only one-third demonstrated appropriate treatment-seeking behaviour, and the rates of appropriate treatment-seeking behaviour did not differ significantly between MV and NMV. Caregivers' knowledge of malaria, malaria prevention behaviour and proximity to public health service were important determinants of appropriate treatment-seeking behaviour. At the same time, treatment at home and total cost for treatment and transportation were negatively associated with appropriate treatment-seeking behaviour. Midwives played an important role in treatment-seeking behaviour, as most caregivers first approached the local midwife for their child's illnesses.

Only about one-third of caregivers demonstrated appropriate treatment-seeking behaviour. Approximately $20 \%$ of the children with fever were not taken to any health services for advice or treatment. This situation appears to be much worse than reported in a study conducted in Wa region in Myanmar, wherein $12.5 \%$ of caregivers did not seek treatment for their child's fever [12]. Despite this, the present study found that participants' treatment-seeking behaviour was more favourable than those in several study sites in other countries [7,25-27].

The delay in seeking treatment and the decision to utilize untrained health services are a grievous concern as only about one-third of the caregivers sought treatment for their children at a health facility or from trained personnel within 24 hours of the onset of fever. Another third had consulted with trained personnel or at health facilities but only after 24 hours. A quarter of all caregivers sought treatment within 24 hours, but from untrained health services including drug stores, charlatans and traditional healers; $8.5 \%$ sought treatment at untrained health services after 24 hours. A study conducted in India showed that children 
Table 5 Determinants of appropriate treatment-seeking behaviour

\begin{tabular}{|c|c|c|}
\hline Variables & AOR & $(95 \% \mathrm{Cl})$ \\
\hline \multicolumn{3}{|l|}{ Type of village } \\
\hline \multicolumn{3}{|l|}{ NMV (ref.) } \\
\hline MV & 0.80 & $(0.51-1.24)$ \\
\hline \multicolumn{3}{|l|}{ Number of children U5 at home } \\
\hline \multicolumn{3}{|l|}{$>1$ (ref.) } \\
\hline 1 & 1.05 & $(0.48-2.30)$ \\
\hline \multicolumn{3}{|l|}{ Children's age (months) } \\
\hline \multicolumn{3}{|l|}{$\leq 27$ (ref.) } \\
\hline$>27$ & 0.70 & $(0.44-1.09)$ \\
\hline \multicolumn{3}{|l|}{ Children's sex } \\
\hline \multicolumn{3}{|l|}{ Female (ref.) } \\
\hline Male & 1.26 & $(0.81-1.93)$ \\
\hline \multicolumn{3}{|l|}{ Caregivers' age (years) } \\
\hline \multicolumn{3}{|l|}{$\leq 30$ (ref.) } \\
\hline$>30$ & 0.75 & $(0.47-1.19)$ \\
\hline \multicolumn{3}{|l|}{ Marital status } \\
\hline \multicolumn{3}{|l|}{ Other (ref.) } \\
\hline Married & 1.70 & $(0.53-5.45)$ \\
\hline \multicolumn{3}{|l|}{ Level of education } \\
\hline \multicolumn{3}{|l|}{ Illiterate (ref.) } \\
\hline Primary school & 0.99 & $(0.38-2.61)$ \\
\hline Secondary school or higher & 1.06 & $(0.37-3.05)$ \\
\hline \multicolumn{3}{|l|}{ Occupation } \\
\hline \multicolumn{3}{|l|}{ Other (ref) } \\
\hline Farmer & 0.87 & $(0.54-1.41)$ \\
\hline Forest worker & 0.80 & $(0.42-1.51)$ \\
\hline \multicolumn{3}{|l|}{ Income (US\$) } \\
\hline \multicolumn{3}{|l|}{$\leq 60$ (ref.) } \\
\hline$>60$ & 1.04 & $(0.65-1.66)$ \\
\hline \multicolumn{3}{|l|}{ Nearest health service } \\
\hline \multicolumn{3}{|c|}{${ }^{* *}$ Inappropriate health service (ref.) } \\
\hline Public health service & 5.86 & $(3.43-10.02)^{*}$ \\
\hline Private health service & 1.69 & $(0.52-5.46)$ \\
\hline \multicolumn{3}{|l|}{ Mode of transportation } \\
\hline By vehicle (ref.) & 1.84 & $(0.94-3.61)$ \\
\hline \multicolumn{3}{|l|}{ On foot } \\
\hline \multicolumn{3}{|l|}{ Proximity to nearest health service } \\
\hline \multicolumn{3}{|l|}{ More than 30 min (ref.) } \\
\hline Within 30 min & 3.42 & $(0.82-14.16)$ \\
\hline \multicolumn{3}{|l|}{ Treatment at home } \\
\hline \multicolumn{3}{|l|}{ No (ref.) } \\
\hline Yes & 0.26 & $(0.15-0.45)^{*}$ \\
\hline
\end{tabular}

Table 5 Determinants of appropriate treatment-seeking behaviour (Continued)

\begin{tabular}{|c|c|c|}
\hline \multicolumn{3}{|c|}{ Total cost (US\$) } \\
\hline \multicolumn{3}{|c|}{$>1.1$ (ref) } \\
\hline$\leq 1.1$ & 0.52 & $(0.33-0.83)^{*}$ \\
\hline \multicolumn{3}{|c|}{ Knowledge level } \\
\hline \multicolumn{3}{|c|}{ Low (ref.) } \\
\hline High & 1.90 & $(1.14-3.17)^{*}$ \\
\hline \multicolumn{3}{|c|}{ Preventive action } \\
\hline \multicolumn{3}{|c|}{ Low (ref.) } \\
\hline High & 1.76 & $(1.13-2.76)^{*}$ \\
\hline
\end{tabular}

under five were at high risk because they had the least timely and least effective treatment for febrile illnesses among all age groups [5].

In this preliminary survey to determine baseline rates, the presence of mobile clinics (MV) was not associated with appropriate treatment-seeking behaviour for children under five. This may be explained by the limited activities conducted by the mobile team and volunteers for the residents of the target villages in the initial stages of intervention. The initial stage included malaria diagnosis for fever patients and treatment specifically for confirmed malaria cases visiting the clinic, wherein only the patients benefitted from their activities that were not extended to meet community needs. Further, circumstances between MV and NMV were not identical despite efforts to match both. That is, MV were selected because of their relatively inaccessible location (remote, bordering forests where malaria vectors breed, and at a great distance from RHCs). The caregivers were inadvertently more familiar with inappropriate health services, such as drug stores, than mobile clinics and village volunteers in rural areas. However, previous studies in Bago Region in Myanmar concluded that having volunteers specifically trained for implementing malaria control programmes can improve accessibility and administration of health care in villages without health staff, although overall they may remain low [18].

One of the behaviours that led to the delay in seeking treatment was treatment at home; almost $50 \%$ of the children with fever were treated at home before seeking treatment outside. Individuals are more likely to begin with self-medication at home to minimize both expenditure and the burden of reaching a facility in remote areas where transportation and health facilities are scarce [28-30]. A high proportion of fever cases were first treated at home with shop-bought drugs before visiting health facilities [31]. Caregivers who administered 
medication at home were not likely to seek appropriate treatment [12], possibly because the child recovered after self-medication and/or other first-aid measures, such as tepid sponging.

Greater awareness about malaria and undertaking a broader range of preventive actions for malaria influence appropriate treatment-seeking behaviour. A study in Cambodia showed that early recognition of malaria symptoms is the first important step to treatment seeking [20]. In the present study, although caregivers were aware of malaria symptoms, about $50 \%$ were unaware that children under five and pregnant mothers are especially vulnerable to malaria. A previous study in Tikekyi township,Yangon region and four townships in Bago region, Myanmar demonstrated that the level of awareness about malaria was low compared to the average score used in the studies [16,32].

The most popular health service providers in this study were midwives, primarily because caregivers' trust them being qualified and experienced health providers [33,34]. Another reason is that midwives have served villagers for longer than the village malaria volunteers [18]. A survey conducted by Myanmar Artemisinin Resistance Containment (MARC) showed that the public sector, including RHCs and midwives, was cited as the most popular source for treatment of malaria [35]. Drug stores also played an important role in the present study, as one-quarter of the caregivers sought treatment from them. A similar situation was observed in sub-Saharan Africa [36]. Proximity to drug stores may have encouraged individuals to use them to save on transportation [37].

Findings from this study should be considered in the context of some limitations. First, caregivers were asked about the fever of their children under five during the previous two months, thus responses might reflect recall bias. Nevertheless, the items utilized in data collection were drawn from validated and reliable instruments that have been used in a variety of settings. Second, this study was unable to explore causal relationships because of a cross-sectional study design.

Despite these limitations, this study is valuable as it identified the determinants of caregivers' treatmentseeking behaviour for children under five presenting with fever in malaria-endemic, rural Myanmar. This study provides baseline findings for the initial stage of the implemented intervention.

\section{Conclusions}

Caregivers' treatment-seeking behaviour was poor for their children under five with fever, as only one-third demonstrated appropriate treatment-seeking behaviour. Further, baseline treatment-seeking behaviour for fever cases did not differ significantly between MV and NMV. Caregivers' knowledge of malaria, malaria prevention behaviour and proximity to public health services were important determinants of appropriate treatmentseeking behaviour. At the same time, treatment at home and total cost for treatment and transportation were negatively associated with appropriate treatmentseeking behaviour. The role of the midwife was important, as most caregivers first sought their assistance for their children's illnesses.

Greater awareness and health education for caregivers are necessary, particularly on early treatment-seeking and appropriate use of health care options for fever. These findings will be utilized to improve the quality of the intervention and will be compared with follow-up data collected at a later stage to evaluate its effectiveness at the community level.

\section{Competing interests}

The authors declare that they have no competing interests.

\section{Authors' contributions}

MT conceived the study, collected data, carried out analysis, and wrote manuscript. JY oversaw data analysis and participated in writing manuscript. MK participated in the design of the study. MJ participated in study designing and overall coordination. All authors read and approved the final manuscript.

\section{Acknowledgements}

We would like to thank the study participants for their immense contribution. We are grateful to Dr Myo Min and the Myanmar Medical Association-Malaria Project for their technical support and extensive advice based on their experiences. We would like to acknowledge the interviewers, local health staff, and village leaders for their assistance during the fieldwork.

\section{Author details}

${ }^{1}$ Community and Global Health Department, Graduate School of Medicine, the University of Tokyo, Tokyo, Japan. ${ }^{2}$ Department of Medical Research (Lower Myanmar), Yangon, Republic of the Union of Myanmar.

Received: 18 September 2014 Accepted: 15 December 2014 Published: 5 January 2015

\section{References}

1. Haque U, Scott LM, Hashizume M, Fisher E, Haque R, Yamamoto T, et al. Modelling malaria treatment practices in Bangladesh using spatial statistics. Malar J. 2012;11:63

2. WHO. World Malaria Report 2013. Geneva: World Health Organization; 2013 3. WHO. 10 facts on malaria. Geneva: World Health Organization; 2014

4. WHO. T3: Test. Treat. Track initiative. Geneva: World Health Organization; 2012.

5. Das A, Ravindran TS. Factors affecting treatment-seeking for febrile illness in a malaria endemic block in Boudh district, Orissa, India: policy implications for malaria control. Malar J. 2010;9:377.

6. Sumba PO, Wong SL, Kanzaria HK, Johnson KA, John CC. Malaria treatmentseeking behaviour and recovery from malaria in a highland area of Kenya. Malar J. 2008;7:245.

7. Hetzel MW, Obrist B, Lengeler C, Msechu JJ, Nathan R, Dillip A, et al. Obstacles to prompt and effective malaria treatment lead to low community-coverage in two rural districts of Tanzania. BMC Public Health. 2008;8:317.

8. Yadav SP, Sharma RC, Joshi V. Study of social determinants of malaria in desert part of Rajasthan, India. J Vector Borne Dis. 2005;42:141-6.

9. Ahmed SM, Haque R, Haque U, Hossain A. Knowledge on the transmission, prevention and treatment of malaria among two endemic populations of Bangladesh and their health-seeking behaviour. Malar J. 2009;8:173. 
10. Lowassa A, Mazigo HD, Mahande AM, Mwang'onde BJ, Msangi S, Mahande MJ, et al. Social economic factors and malaria transmission in Lower Moshi, northern Tanzania. Parasit Vectors. 2012;5:129.

11. Oberlander L, Elverdan B. Malaria in the United Republic of Tanzania: cultural considerations and health-seeking behaviour. Bull World Health Organ. 2000;78:1352-7.

12. Xu JW, Xu QZ, Liu H, Zeng YR. Malaria treatment-seeking behaviour and related factors of Wa ethnic minority in Myanmar: a cross-sectional study. Malar J. 2012;11:417.

13. Getahun A, Deribe K, Deribew A. Determinants of delay in malaria treatment-seeking behaviour for under-five children in south-west Ethiopia: a case control study. Malar J. 2010;9:320.

14. UNICEF. Country Program Overview 2011-2015;

15. National Malaria Control Programme, Myanmar. Malaria Situation in Myanmar; 2010.

16. Kyawt Kyawt S, Pearson A. Knowledge, attitudes and practices with regard to malaria control in an endemic rural area of Myanmar. Southeast Asian J Trop Med Public Health. 2004;35:53-62.

17. Myanmar $\mathrm{MOH}$. Annual Vector Borne Disease Contol (VBDC) Programme Data; 2011.

18. Ohnmar, Tun M, San S, Than W, Chongsuvivatwong V. Effects of malaria volunteer training on coverage and timeliness of diagnosis: a cluster randomized controlled trial in Myanmar. Malar J. 2012:11:309.

19. WHO. Malaria Indicator Survey; 2013.

20. Lim S, Yasuoka J, Poudel KC, Ly P, Nguon C, Jimba M. Promoting community knowledge and action for malaria control in rural Cambodia: potential contributions of Village Malaria Workers. BMC Res Notes. 2012;5:405.

21. Hasegawa A, Yasuoka J, Ly P, Nguon C, Jimba M. Integrating child health services into malaria control services of village malaria workers in remote Cambodia: service utilization and knowledge of malaria management of caregivers. Malar J. 2013;12:292.

22. Yasuoka J, Poudel KC, Poudel-Tandukar K, Nguon C, Ly P, Socheat D, et al. Assessing the quality of service of village malaria workers to strengthen community-based malaria control in Cambodia. Malar J. 2010;9:109.

23. Yasuoka J, Poudel KC, Ly P, Nguon C, Socheat D, Jimba M. Scale-up of community-based malaria control can be achieved without degrading community health workers' service quality: the Village Malaria Worker project in Cambodia. Malar J. 2012;11:4.

24. WHO. Roll Back Malaria; 2005

25. Smith LA, Bruce J, Gueye L, Helou A, Diallo R, Gueye B, et al. From fever to anti-malarial: the treatment-seeking process in rural Senegal. Malar J. 2010;9:333.

26. Amin AA, Marsh V, Noor AM, Ochola SA, Snow RW. The use of formal and informal curative services in the management of paediatric fevers in four districts in Kenya. Trop Med Int Health. 2003;8:1143-52.

27. Rutebemberwa E, Pariyo G, Peterson S, Tomson G, Kallander K. Utilization of public or private health care providers by febrile children after user fee removal in Uganda. Malar J. 2009:8:45.

28. Nyamongo IK. Health care switching behaviour of malaria patients in a Kenyan rural community. Soc Sci Med. 2002;54:377-86.

29. Thera MA, D'Alessandro U, Thiero M, Ouedraogo A, Packou J, Souleymane $O A$, et al. Child malaria treatment practices among mothers in the district of Yanfolila, Sikasso region, Mali. Trop Med Int Health. 2000;5:876-81.

30. Ruebush TK, Kern MK, Campbell CC, Oloo AJ. Self-treatment of malaria in a rural area of western Kenya. Bull World Health Organ. 1995;73:229-36.

31. Snow RWPN, Forster D, Mwenesi H, Marsh K. The role of shops in the treatment and prevention of childhood malaria on the coast of Kenya. Trans R Soc Trop Med Hyg. 1992;86:237-9.

32. Ohnmar, Tun M, May Aye T, San S, Wai Wai M, Chongsuvivatwong V. Access to a blood test and antimalarials after introducing rapid diagnostic tests in rural Myanmar: initial experience in a malaria endemic area. Int Health. 2010:2:275-81.

33. Abuya TO, Mutemi W, Karisa B, Ochola SA, Fegan G, Marsh V. Use of over-thecounter malaria medicines in children and adults in three districts in Kenya: implications for private medicine retailer interventions. Malar J. 2007;6:57.

34. Ajayi 1O, Browne EN, Garshong B, Bateganya F, Yusuf B, Agyei-Baffour P, et al. Feasibility and acceptability of artemisinin-based combination therapy for the home management of malaria in four African sites. Malar J. 2008;7:6.
35. Beyl C, Kyaw M, Ohnmar, Maung T, Meek S, Thimasarn K, et al. Myanmar Artemisinin Resistance Containment (MARC) survey: malaria diagnosis and treatment. Washington: Poster, 62nd ASTMH Annual Meeting; 2013.

36. Goodman C, Brieger W, Unwin A, Mills A, Meek S, Greer G. Medicine sellers and malaria treatment in sub-Saharan Africa: what do they do and how can their practice be improved? Am J Trop Med Hyg. 2007;77:203-18.

37. Schellenberg JA, Victora CG, Mushi A, de Savigny D, Schellenberg D, Mshinda $\mathrm{H}_{\text {, et }}$ al. Inequities among the very poor: health care for children in rural southern Tanzania. Lancet. 2003;361:561-6.

doi:10.1186/1475-2875-14-1

Cite this article as: Thandar et al:: Caregivers' treatment-seeking behaviour for children under age five in malaria-endemic areas of rural Myanmar: a cross-sectional study. Malaria Journal 2015 14:1.

\section{Submit your next manuscript to BioMed Central and take full advantage of:}

- Convenient online submission

- Thorough peer review

- No space constraints or color figure charges

- Immediate publication on acceptance

- Inclusion in PubMed, CAS, Scopus and Google Scholar

- Research which is freely available for redistribution 